\title{
Anti-inflammatory effects of olanexidine gluconate on oral epithelial cells
}

\author{
Takuya Nii ${ }^{*}$ (D), Hiromichi Yumoto ${ }^{2}$, Katsuhiko Hirota ${ }^{3,4}$ and Yoichiro Miyake 3,5
}

\begin{abstract}
Background: Periodontitis is a biofilm-induced chronic inflammatory condition of the periodontium. Chemokines produced by the innate and acquired immune responses play a significant role in disease progression. Reducing biofilm formation and inflammatory response caused by chemokines is vital for preventing and treating periodontitis. Previously, we observed that treatment with $0.1 \%$ olanexidine gluconate (OLG) inhibited biofilm formation on saliva-coated hydroxyapatite. This study aimed to evaluate the antiinflammatory effect of OLG on oral epithelial cells.

Methods: We examined if OLG could inhibit the inflammatory responses caused by Porphyromonas gingivalis (P. gingivalis) lipopolysaccharide (LPS) and heat-killed $P$. gingivalis in immortalized human oral keratinocytes (RT7).

Results: Treatment of RT7 with non-cytotoxic OLG concentrations significantly inhibited the production of inflammatory chemokines such as interleukin 8 (IL-8), C-C motif ligand 20 (CCL20), and growth-related oncogene protein- $a(G R O-a)$, which are stimulated by $P$. gingivalis LPS in a concentration-dependent manner. Moreover, the inhibitory effects were observed regardless of the treatment time with $P$. gingivalis LPS $(6,12$, or $24 \mathrm{~h}$ ). OLG also significantly inhibited chemokine production stimulated by heat-killed $P$. gingivalis.
\end{abstract}

Conclusions: The findings of this study suggest that treatment with OLG inhibits chronic inflammatory reactions in oral mucosal cells, such as periodontitis, caused by oral bacteria.

Keywords: Olanexidine gluconate, Porphyromonas gingivalis lipopolysaccharide, Keratinocytes

\section{Background}

Periodontitis is a chronic inflammatory condition triggered by microbial biofilm formation in the periodontal pocket, which induces periodontal tissue destruction and leads to tooth loss [1]. The inflammatory response in periodontitis is initiated by the innate immune response and progresses by the acquired and innate immune responses. Both immune responses are regulated by many factors, including chemokines that are involved in the migration of phagocytic cells to the site of infection. Therefore, to prevent and treat periodontitis, biofilm formation and the inflammatory response to chemokines must be reduced.

\footnotetext{
* Correspondence: nii.takuya@otsuka.jp

${ }^{1}$ Naruto Research Institute, Research and Development Center, Otsuka Pharmaceutical Factory, Inc, Takuya Nii, 115 Kuguhara, Tateiwa, Muya-cho, Naruto, Tokushima 772-8601, Japan

Full list of author information is available at the end of the article
}

The innate immune response is initiated by toll-like receptors (TLRs) when biofilm-forming bacteria, such as Porphyromonas gingivalis infect the periodontal tissue $[2,3]$. TLRs recognize various bacterial products called pathogen-associated molecular patterns (PAMPs), including lipopolysaccharide (LPS). Both in vitro and in vivo studies have reported that TLRs are expressed in the human gingival epithelium [4-7]. TLRs, which are highly expressed in the epithelial cells of the periodontal pocket tissue, were reported to recognize PAMPs of $P$. gingivalis and participate in the signaling pathway that induces the production of chemokines, such as interleukin-8 (IL-8) $[4,5]$.

IL-8 is produced during the initial steps of the inflammatory response and plays a crucial role in the recruitment and activation of neutrophils, which are major contributors to tissue damage during inflammatory diseases $[8-10]$. In recent years, growth-related oncogene

(c) The Author(s). 2019 Open Access This article is distributed under the terms of the Creative Commons Attribution 4.0 International License (http://creativecommons.org/licenses/by/4.0/), which permits unrestricted use, distribution, and 
protein- $\alpha$ (GRO- $\alpha)$ has been recognized for its chemotactic activity on neutrophils [11]. In a three-dimensional coculture model of gingival epithelial cells, the expression levels of GRO- $\alpha$ were elevated in response to increasing inflammatory reactions [12]. Apart from the innate responses, the acquired immune response involving the invasion of T-cells and B-cells is also known to be involved in periodontitis.

The role of T helper type 17 (Th17) cells in the acquired immune response was recently reported, and their presence in periodontal tissue was confirmed [13]. The chemokine C-C motif ligand 20 (CCL20) is known to regulate Th17 cell migration and infiltration [14] and its expression, particularly in the basal layer of inflamed gingival epithelial cells, has been previously reported [15]. Therefore, the inhibition of chemokines appears to be essential in the treatment and prevention of periodontitis.

Olanedine antiseptic solution 1.5\% (Olanedine, Fig. 1) was launched in 2015 as an antiseptic for preoperative skin preparation. It contains olanexidine gluconate (OLG) [1-(3, 4-dichlorobenzyl)-5-octylbiguanide gluconate] as an active ingredient. Olanedine is more effective bactericide than existing antiseptics in sites contaminated with blood [16] and acts against a broad spectrum of bacteria, including some that are drug-resistant $[17,18]$. Besides, Olanedine has fast-acting and long-lasting bactericidal effects [16]. Based on these characteristics, OLG is considered an effective chemical plaque control agent in oral hygiene management.

In a previous study, we observed that $0.1 \%$ OLG inhibited the adherence of Streptococcus mutans on saliva-coated hydroxyapatite (HA) pellets. The results suggested that OLG covered the surface and reduced the hydrophobic interactions between $S$. mutans and saliva-coated HA-pellets, which form the salivary pellicle (unpublished). Since OLG can coat the surface and has a high binding affinity for LPS [17], we hypothesized that $0.1 \%$ OLG could inhibit the inflammatory response induced by bacteria or LPS stimulation, including the production of IL-8, GRO- $\alpha$, and CCL20, in the oral mucosal epithelium. These anti-inflammatory effects might be valuable in preventing and treating periodontitis. Therefore, in this study, we examined if OLG inhibited the

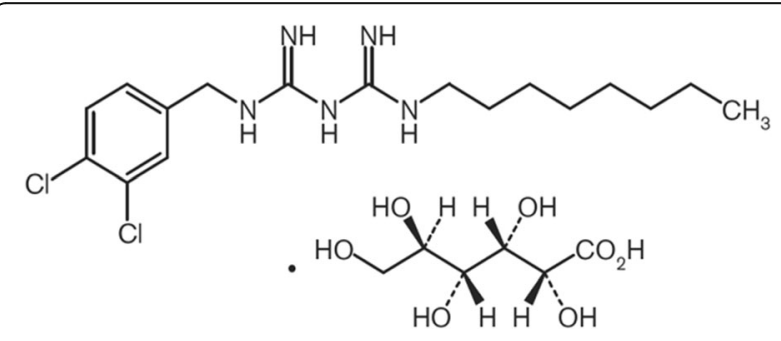

Fig. 1 Chemical structure of Olanedine inflammatory reactions caused by $P$. gingivalis LPS or heatkilled $P$. gingivalis using immortalized human oral keratinocytes (RT7).

\section{Methods \\ Cell lines and reagents}

The $0.1 \%$ OLG formulation (Fig. 1) was composed of the solubilizing agent, polyoxyethylene polyoxypropylene glycol (POEPOPG), and the active ingredient olanexidine, and was prepared by Otsuka Pharmaceutical Factory, Inc. (Tokushima, Japan). Dilutions were prepared with phosphate buffered saline (PBS). The RT7 cell line, kindly provided by Dr. N. Kamata (Hiroshima University, Japan), was cultured in Keratinocyte-SFM (Thermo Fisher Scientific, MA, US) as described previously [19]. P. gingivalis strain ATCC 33277 was obtained from ATCC (Manassas, VA, US) and cultured in brain-heart infusion broth (Difco, Detroit, MI, US) supplemented with $0.5 \%$ yeast extract (Difco), hemin $(10 \mu \mathrm{g} / \mathrm{mL})$, and vitamin $\mathrm{K}(1 \mu \mathrm{g} / \mathrm{mL})$ and harvested in the stationary phase. Bacterial numbers were determined spectrophotometrically using a standard curve adjusted with PBS ( $\mathrm{pH} 7.4)$. Heat-killed $P$. gingivalis was prepared by heating a bacterial suspension $\left(\sim 1 \times 10^{9}\right.$ cells $/ \mathrm{mL}$ ) for $10 \mathrm{~min}$ at $65^{\circ} \mathrm{C}$. P. gingivalis LPS purified by a standard preparation is a TLR2 and TLR4-specific ligand and was commercially obtained from InvivoGen (San Diego, CA, US).

\section{Cytotoxicity test}

RT7 were cultured to confluent monolayers in 24-well plates. After the aspiration of the medium, $0.2 \mathrm{~mL}$ of OLG at each concentration was added to the RT7 monolayer in each well and left to stand for $1 \mathrm{~min}$ at room temperature (RT). After the aspiration of OLG, fresh medium $(0.5 \mathrm{~mL} /$ well) was added and RT7 monolayers were cultured further. After 6, 12, and $24 \mathrm{~h}$ of cultivation, total culture supernatants were collected to determine the concentration of lactate dehydrogenase (LDH) using the LDH cytotoxicity assay kit (Cayman Chemical Co., MI, US). At $24 \mathrm{~h}$, the cell morphology of the cultures was observed using an inverted microscope (Nikon ECLIPSE TS100LED-F, Tokyo, Japan). RT7 monolayers, treated with $0.1 \%$ Triton $\mathrm{X}-100$ for $10 \mathrm{~min}$ at $\mathrm{RT}$, were used as a positive control in the cytotoxicity test.

\section{Measurement of inflammatory chemokines}

We added fresh medium with $1 \mu \mathrm{g} / \mathrm{mL} P$. gingivalis LPS $(0.5 \mathrm{~mL} /$ well) to RT7 monolayers treated with 10 or $50 \mu \mathrm{g} /$ mL OLG (1 min at RT). After 6,12 , and $24 \mathrm{~h}$ of incubation, total culture supernatants were collected to determine the concentration of IL-8, CCL20, and GRO- $\alpha$ using an ELISA kit (R\&D systems, MN, US). To measure the cytokines stimulated with heat-killed $P$. gingivalis, fresh medium containing heat-killed $P$. gingivalis at a multiplicity of infection 


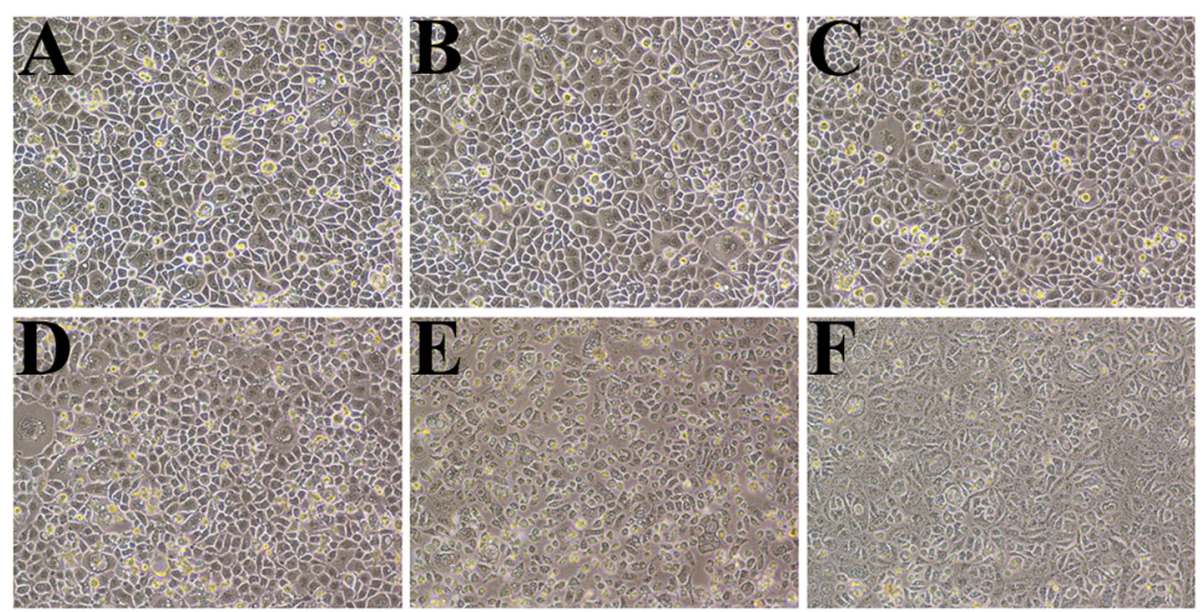

Fig. 2 Morphology of RT7 monolayers $24 \mathrm{~h}$ after treatment ( $1 \mathrm{~min}$ ) with OLG. Each panel shows a representative photograph of the different treatments. Cytotoxicity was not observed in the control (a) and after treatment with $10 \mu \mathrm{g} / \mathrm{mL}$ (b) and $50 \mu \mathrm{g} / \mathrm{mL}$ (c) OLG, while morphological changes were observed after treatment with $100 \mu \mathrm{g} / \mathrm{mL}$ (d), $250 \mu \mathrm{g} / \mathrm{mL}$ (e), and $500 \mu \mathrm{g} / \mathrm{mL}$ (f) OLG. OLG: olanexidine gluconate
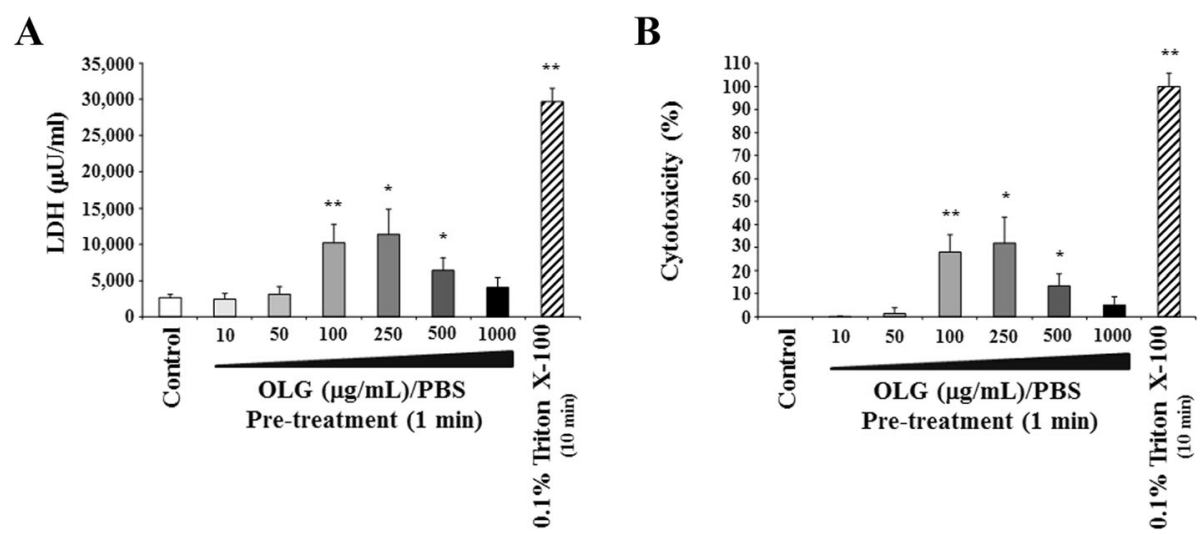

Fig. $3 \mathrm{LDH}$ measurement (a) and cytotoxicity (b) $24 \mathrm{~h}$ after treatment with OLG (1 min). Cytotoxicity was not observed after treatment with 10 , 50 , and $1000 \mu \mathrm{g} / \mathrm{mL}$ OLG when compared to the control. The values are expressed as the mean \pm standard deviation of four replicate measurements. ${ }^{*}(p<0.05)$ and ${ }^{* *}(p<0.01)$ show significant differences when compared to the control. LDH: lactate dehydrogenase; OLG: olanexidine gluconate

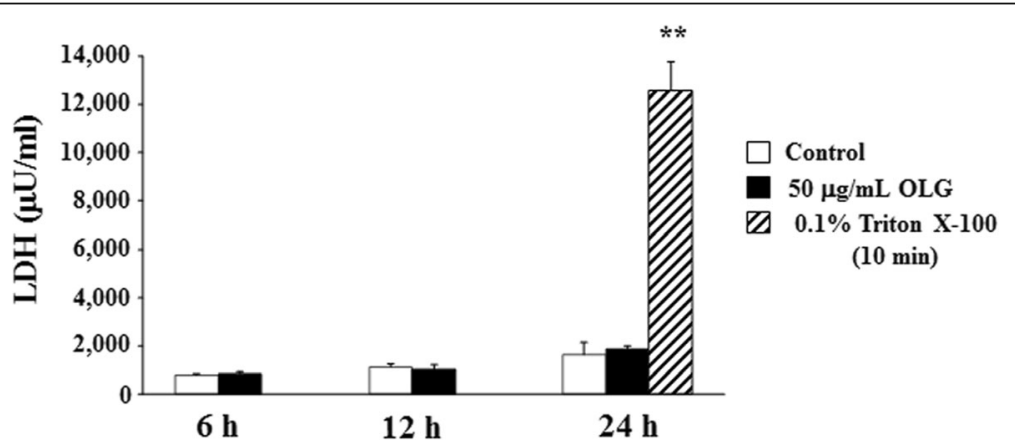

Fig. $4 \mathrm{LDH}$ measurement at different time points after 1 min treatment with $50 \mu \mathrm{g} / \mathrm{mL}$ OLG. Cytotoxicity was not observed at 6, 12, and 24 h. The values are expressed as the mean \pm standard deviation of four replicate measurements. ${ }^{* *}(p<0.01)$ shows significant difference when compared to the control. LDH: lactate dehydrogenase; OLG: olanexidine gluconate 
(MOI) of 10 were added to the RT7 monolayer treated with $50 \mu \mathrm{g} / \mathrm{mL}$ OLG (1 min at RT).

\section{Statistical analysis}

All statistical analyses were performed using the unpaired Student's $t$-test and GraphPad Prism (GraphPad Software, Inc. La Jolla, CA, USA). Differences were considered significant when the probability value was less than $5 \%(p<0.05)$.

\section{Results}

\section{Cytotoxicity of OLG on oral epithelial cells}

OLG concentrations less than or equal to $50 \mu \mathrm{g} / \mathrm{mL}$ showed no cytotoxic effects on the morphology of the cells (Fig. 2). The LDH concentrations corroborated this observation (Figs. 3 and 4). Upon morphological analysis, cytotoxicity was observed at concentrations higher than $100 \mu \mathrm{g} / \mathrm{mL}$ OLG; however, no LDH cytotoxicity was observed even at $1000 \mu \mathrm{g} / \mathrm{mL}$ OLG.

Inhibitory effect of OLG on the production of chemokines IL-8, CCL20, and GRO-a

OLG treatment significantly inhibited the production of IL-8, CCL20, and GRO- $\alpha$ after $24 \mathrm{~h}$ of stimulation by $P$. gingivalis LPS in a concentration-dependent manner (Fig. 5). Furthermore, treatment with $50 \mu \mathrm{g} / \mathrm{mL}$ OLG significantly inhibited the production of chemokines after stimulation by $1 \mu \mathrm{g} / \mathrm{mL} P$. gingivalis LPS at all time points $(6,12$, and $24 \mathrm{~h})$ (Fig. 6).

As observed with $P$. gingivalis LPS, $50 \mu \mathrm{g} / \mathrm{mL}$ OLG treatment significantly inhibited the production of IL-8, CCL20, and GRO- $\alpha$ after stimulation for $24 \mathrm{~h}$ with heatkilled $P$. gingivalis (Fig. 7).

\section{Discussion}

We examined the cytotoxic effects of OLG on RT7 and whether OLG inhibited the inflammatory responses stimulated by $P$. gingivalis LPS or heat-killed $P$. gingivalis. Microscopic observation of cell morphology and the LDH cytotoxicity assay showed that up to $50 \mu \mathrm{g} / \mathrm{mL}$ of OLG (1 $\mathrm{min}$ at RT) were non-cytotoxic. Inconsistencies among the results of morphological analysis and LDH cytotoxicity analysis at $1000 \mu \mathrm{g} / \mathrm{mL}$ OLG could be due to the mode of action of OLG, which causes protein denaturation as is common in other antiseptics.

Recent research indicated that OLG disrupts bacterial membrane integrity and denatures proteins at relatively high concentrations $(\geq 160 \mu \mathrm{g} / \mathrm{mL})$ [17]. High concentrations of OLG could aggregate RT7 cells by protein denaturation, which prevents the release of LDH. Therefore, the amount of LDH released at 500 and $1000 \mu \mathrm{g} /$ $\mathrm{mL}$ of OLG would be less than that released at $250 \mu \mathrm{g} /$ $\mathrm{mL}$ or lower concentrations. To validate this, we confirmed that the released LDH was detected in the

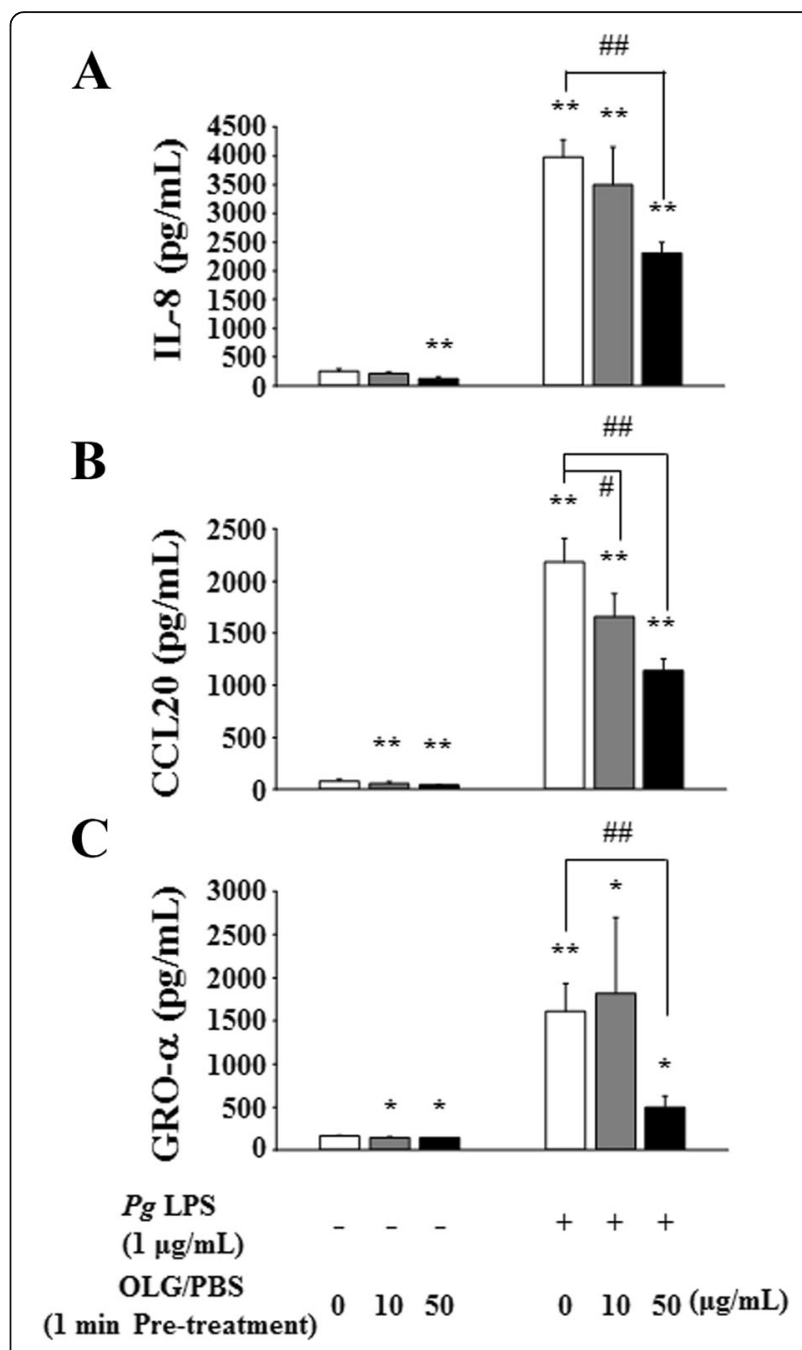

Fig. 5 OLG inhibited chemokine production in RT7 stimulated by $P$. gingivalis LPS for $24 \mathrm{~h}$. Treatment with 10 and $50 \mu \mathrm{g} / \mathrm{mL}$ OLG significantly inhibited the production of interleukin 8 (IL-8) (a) and CC motif ligand 20 (CCL20) (b) in a concentration-dependent manner and treatment with $50 \mu \mathrm{g} / \mathrm{mL}$ OLG significantly inhibited the production of growth-related oncogene protein-a (GRO-a) (c). The values are expressed as the mean \pm standard deviation of four replicate measurements. ${ }^{*}(p<0.05)$ and ${ }^{* *}(p<0.01)$ show significant differences when compared to the non-stimulated control. \# $(p<0.05)$ and \#\# $(p<0.01)$ show significant differences when compared to the control stimulated by $P$. gingivalis. OLG: olanexidine gluconate; Pg: P. gingivalis; LPS: lipopolysaccharide

discarded medium after 1 min treatment of OLG (data not shown). When we analyzed the effects of long-term exposure (8-24h at RT) to OLG, we detected cytotoxicity at lower concentrations $(\geq 5 \mu \mathrm{g} / \mathrm{mL})$. However, the results of this study suggest that a short exposure period of approximately $1 \mathrm{~min}$ is sufficient for the antiseptic to have an adequate effect, and therefore it would not be necessary to use it in conditions that would cause cytotoxicity. 


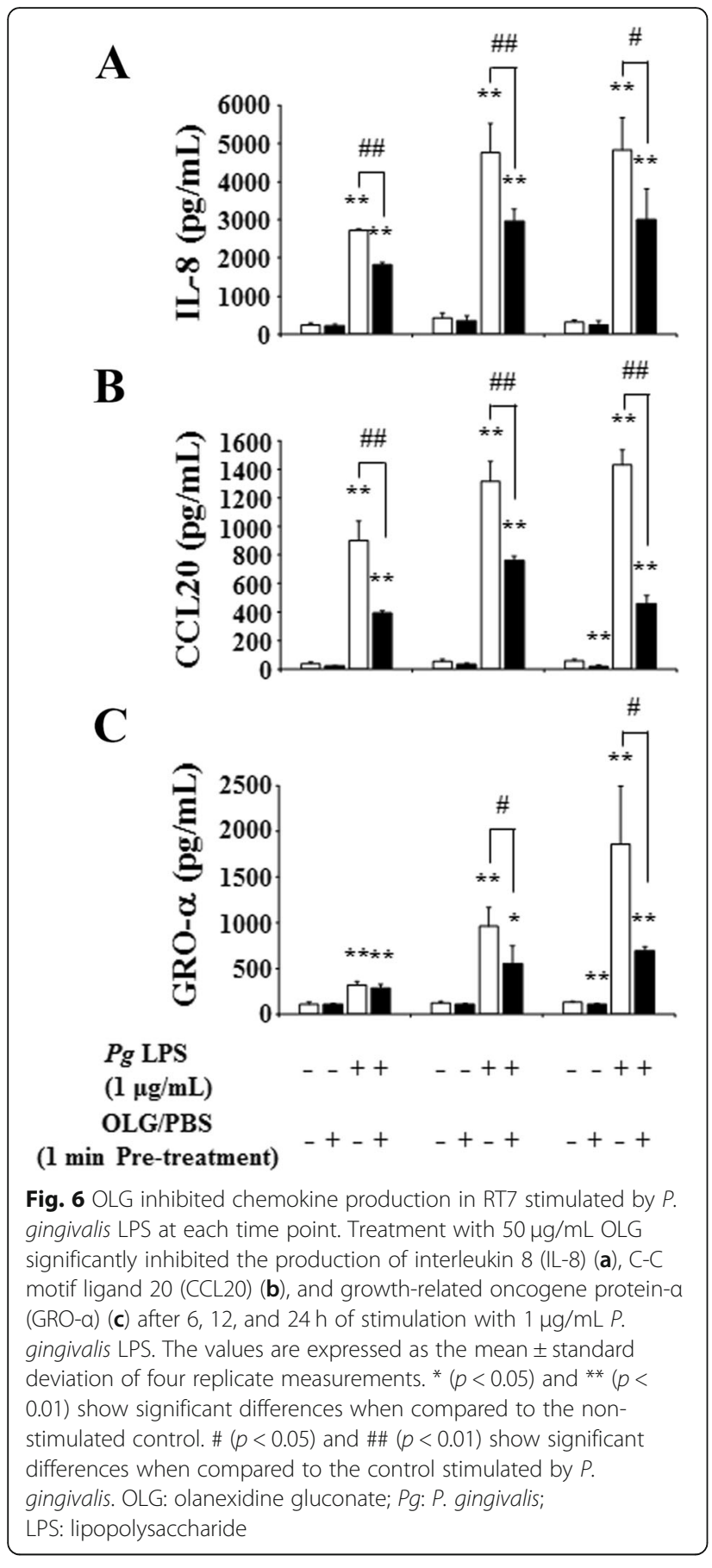

Concerning the inflammatory responses, it was reported that oral and gingival epithelial cells stimulated with $P$. gingivalis LPS or heat-killed $P$. gingivalis had an increased mRNA expression and secretion of proinflammatory cytokines, including IL-8 [20-22]. In this study, the measurement of inflammatory chemokine levels showed that OLG at 10 and $50 \mu \mathrm{g} / \mathrm{mL}$ significantly inhibited the production of IL-8, CCL20, and GRO- $\alpha$ in RT7 cells stimulated with $P$. gingivalis LPS or heat-killed

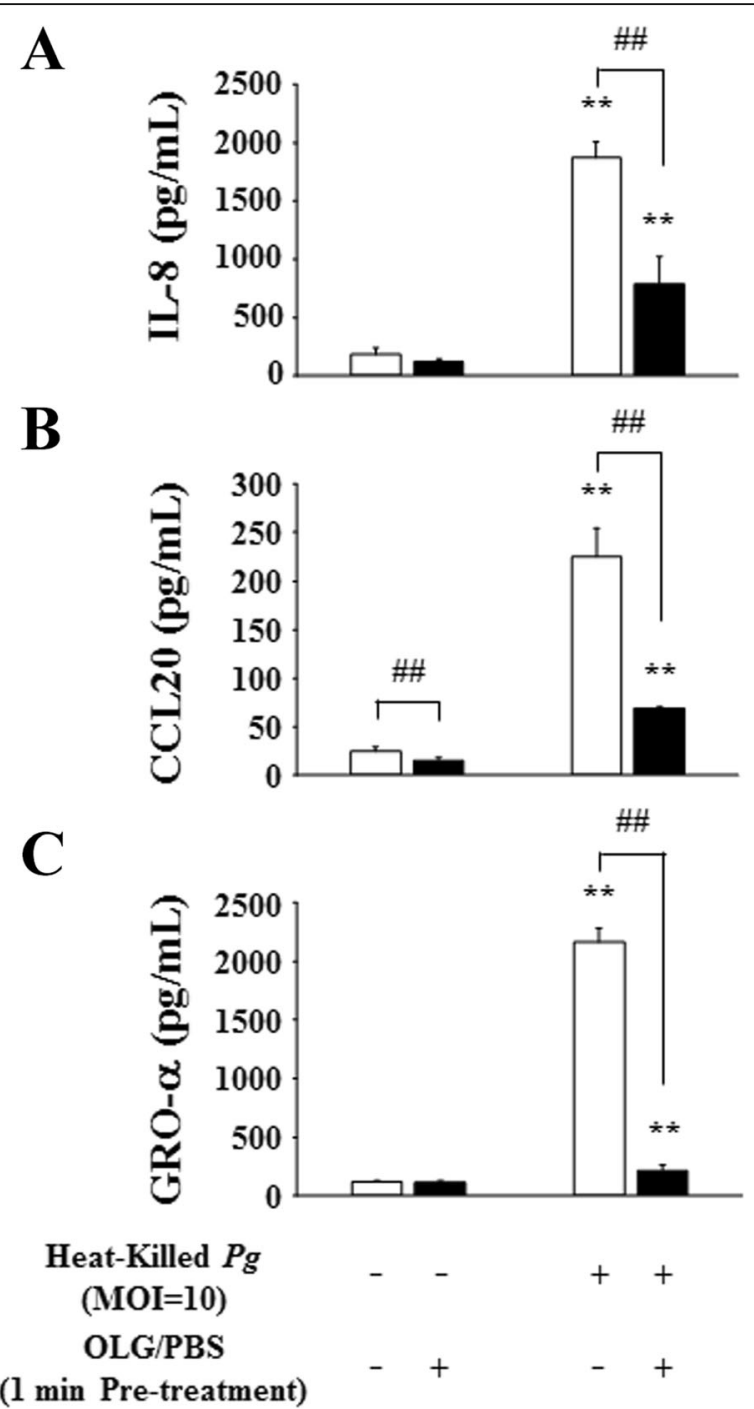

Fig. 7 OLG inhibited chemokine production in RT7 stimulated by heat-killed $P$. gingivalis. Treatment with $50 \mu \mathrm{g} / \mathrm{mL}$ OLG significantly inhibited the production of interleukin 8 (IL-8) (a), C-C motif ligand 20 (CCL20) (b), and growth-related oncogene protein-a (GRO-a) (c) after $24 \mathrm{~h}$ of stimulation by heat-killed $P$. gingivalis $(\mathrm{MOI}=10)$. The values are expressed as the mean \pm standard deviation of four replicate measurements. ${ }^{* *}(p<0.01)$ shows significant differences when compared to the non-stimulated control. \#\# $(p<0.01)$ shows significant differences when compared to the control stimulated by heat-killed $P$. gingivalis. OLG: olanexidine gluconate; Pg: $P$. gingivalis; MOl: multiplicity of infection

P. gingivalis. We performed the same experiment using Escherichia coli LPS (ultrapure LPS, E. coli 0111:B4, InvivoGen, San Diego, CA, US) to determine whether the anti-inflammatory effects of OLG were $P$. gingivalis LPSspecific. Results for E. coli LPS were the same as for $P$. gingivalis LPS; 10 and $50 \mu \mathrm{g} / \mathrm{mL}$ OLG significantly inhibited the production of IL-8, CCL20, and GRO- $\alpha$ in $E$. coli LPS-stimulated RT7 cells (Fig. 8). Considering past report [17], our results suggest that OLG inhibits LPS- 
A

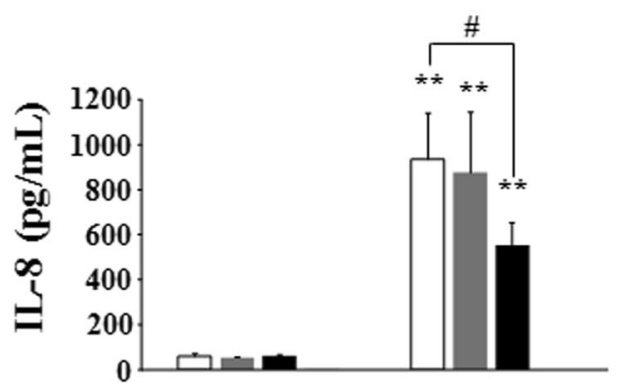

B

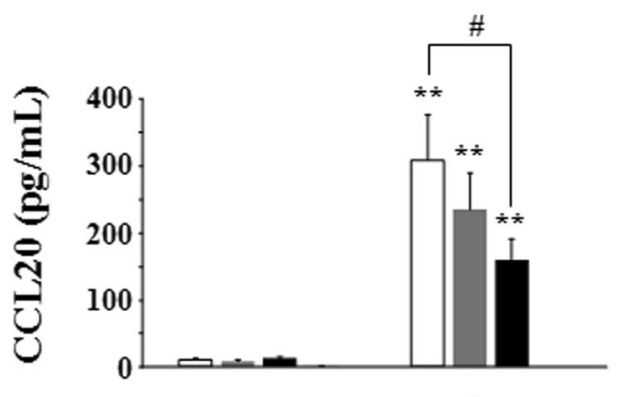

$\mathrm{C}$

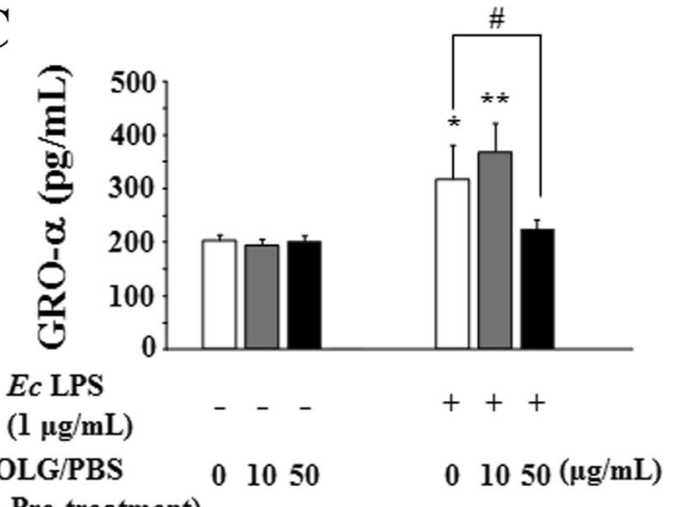

(1 min Pre-treatment)

Fig. 8 OLG inhibited chemokine production in RT7 stimulated by $E$. coli LPS for $24 \mathrm{~h}$. Treatment with 10 and $50 \mu \mathrm{g} / \mathrm{mL}$ OLG significantly inhibited the production of interleukin 8 (IL-8) (a) and C-C motif ligand 20 (CCL20) (b) in a concentration-dependent manner and treatment with $50 \mu \mathrm{g} / \mathrm{mL}$ OLG significantly inhibited the production of growth-related oncogene protein-a (GRO-a) (c). The values are expressed as the mean \pm standard deviation of four replicate measurements. ${ }^{*}(p<0.05)$ and ${ }^{* *}(p<0.01)$ indicate significant differences when compared to the non-stimulated control. \# ( $p<$ 0.05) shows significant differences when compared to the control stimulated by E. coli. OLG: olanexidine gluconate; Ec: E. coli; LPS: lipopolysaccharide

induced inflammation in RT7 cells regardless of the bacterial species. In some experiments, the statistical data show minimal differences between untreated samples and those treated with OLG, even in cases of non-stimulation with $P$. gingivalis LPS or heat-killed $P$. gingivalis. However, we considered that there are no physiological differences based on the initial low expression levels of the different chemokines.
Chlorhexidine, one of the most effective antiseptics, was also reported to inhibit the inflammatory chemokine IL-8 at both mRNA and protein levels in oral epithelial cells. This effect conforms to the mechanism of action of chlorhexidine, which shows an immediate bactericidal activity, combined with prolonged bacteriostatic action, due to absorption on the active surface [23, 24]. Further experiments such as the analysis of the mRNA expression of TLR2 or 4 are needed to understand the mechanism underlying OLG anti-inflammatory action entirely. However, the results of this study and previous studies suggest that OLG exhibits inhibitory effects on the oral inflammatory response to LPS from $P$. gingivalis, a major pathogen causing periodontitis, by forming a protective layer over the gingival epithelial cells and through its bactericidal activity.

To fully understand the effects of utilizing $0.1 \%$ OLG in the clinical practice, we would need to perform in vivo studies. However, since chlorhexidine has been approved for the management of gingivitis, the use of $0.1 \%$ OLG as a new chemical plaque-control agent for oral hygiene management to prevent oral infections, including dental caries and periodontal diseases, should be expected in the future.

\section{Conclusion}

OLG treatment inhibited the production of chemokines IL-8, CCL20, and GRO- $\alpha$ in oral epithelial cells stimulated with $P$. gingivalis LPS or heat-killed $P$. gingivalis in vitro.

\section{Abbreviations}

CCL20: C-C motif ligand 20; GRO-a: Growth-related oncogene protein- $\alpha_{\text {; }}$ HA: Hydroxyapatite; IL-8: Interleukin 8; LDH: Lactate dehydrogenase; LPS: Lipopolysaccharide; MOI: Multiplicity of infection; OLG: Olanexidine gluconate; P. gingivalis: Porphyromonas gingivalis; PAMPs: Pathogenassociated molecular patterns; PBS: Phosphate buffered saline; POEPOPG: Polyoxyethylene polyoxypropylene glycol; RT: Room temperature; RT7: immortalized human oral keratinocytes; Th17: T helper type 17; TLRs: Toll-like receptors

\section{Acknowledgements}

We would like to thank Dr. N. Kamata (Hiroshima University, Japan) for kindly providing the RT7 cell line, Editage (www.editage.jp) for English language editing, and Hiroko Inoue and Yoshie Tsubotani (Otsuka Pharmaceutical Factory, Inc., Japan) for their helpful suggestions.

\section{Authors' contributions}

$\mathrm{TN}$ : participated in the research conception and was responsible for writing the manuscript. HY: participated in the research design, performed the experimental studies on $P$. gingivalis and the statistical analysis and supervised the writing of the manuscript. $\mathrm{KH}$ and YM: participated in the research design and supervised the writing of the manuscript. All authors read and approved the final manuscript.

\section{Funding}

This collaborative work between Tokushima University Graduate School and Otsuka Pharmaceutical Factory, Inc. was funded by Otsuka Pharmaceutical Factory, Inc. The funding body contributed to the conception of the study and writing of the manuscript. Additionally, one of its employees acted as the correspondent author. 


\section{Availability of data and materials}

The datasets used and/or analyzed during the current study are available from the corresponding author on reasonable request.

\section{Ethics approval and consent to participate}

To establish RT7 cell line, buccal mucosal epithelial cells was collected from a healthy adult volunteer who gave a written informed consent following the guidance of the Ethics Committee of Tokushima University Hospital.

\section{Consent for publication}

Not applicable.

\section{Competing interests}

TN is an employee of Otsuka Pharmaceutical Factory, Inc., which founded this study.

\section{Author details}

1 Naruto Research Institute, Research and Development Center, Otsuka Pharmaceutical Factory, Inc, Takuya Nii, 115 Kuguhara, Tateiwa, Muya-cho, Naruto, Tokushima 772-8601, Japan. ${ }^{2}$ Department of Periodontology and Endodontology, Institute of Biomedical Sciences, Tokushima University Graduate School, Tokushima, Japan. ${ }^{3}$ Department of Oral Microbiology, Institute of Biomedical Sciences Tokushima University, Tokushima, Japan. ${ }^{4}$ Present Address: Department of Medical Hygiene, Dental Hygiene Course, Kochi Gakuen College, Kochi, Japan. ${ }^{5}$ Present Address: Department of Oral Health Sciences, Faculty of Health and Welfare, Tokushima Bunri University, Tokushima, Japan.

Received: 6 January 2019 Accepted: 21 October 2019 Published online: 08 November 2019

\section{References}

1. Offenbacher S. Periodontal diseases: pathogenesis. Ann Periodontol. 1996;1: 821-78.

2. Hirschfeld M, Weis JJ, Toshchakov V, Salkowski CA, Cody MJ, Ward DC, et al. Signaling by toll-like receptor 2 and 4 agonists results in differential gene expression in murine macrophages. Infect Immun. 2001:69:1477-82.

3. Holt SC, Kesavalu L, Walker S, Genco CA. Virulence factors of Porphyromonas gingivalis. Periodontol 2000. 1999;20:168-238.

4. Ren L, Leung WK, Darveau RP, Jin L. The expression profile of lipopolysaccharide-binding protein, membrane-bound CD14, and toll-like receptors 2 and 4 in chronic periodontitis. J Periodontol. 2005;76:1950-9.

5. Kusumoto Y, Hirano H, Saitoh K, Yamada S, Takedachi M, Nozaki T, et al. Human gingival epithelial cells produce chemotactic factors interleukin-8 and monocyte chemo attractant protein-1 after stimulation with Porphyromonas gingivalis via toll-like receptor 2. J Periodontol. 2004;75:370-9.

6. Sugawara Y, Uehara A, Fujimoto Y, Kusumoto S, Fukase K, Shibata K, et al. Toll-like receptors, NOD1, and NOD2 in oral epithelial cells. J Dent Res. 2006; 85:524-9.

7. Beklen A, Hukkanen M, Richardson R, Konttinen YT. Immunohistochemical localization of toll-like receptors 1-10 in periodontitis. Oral Microbiol Immunol. 2008;23:425-31.

8. Baggiolini M. Chemokines and leukocyte traffic. Nature. 1998;392:565-8.

9. Mitchell GB, Albright BN, Caswell JL. Effect of interleukin-8 and granulocyte colony-stimulating factor on priming and activation of bovine neutrophils. Infect Immun. 2003;71:1643-9.

10. Baggiolini M, Dewald B, Moser B. Interleukin-8 and related chemotactic cytokines--CXC and CC chemokines. Adv Immunol. 1994;55:97-179.

11. Moser B, Clark-Lewis I, Zwahlen R, Baggiolini M. Neutrophil-activating properties of the melanoma growth-stimulatory activity. J Exp Med. 1990; 171:1797-802.

12. Lombardo Bedran TB, Palomari Spolidorio D, Grenier D. Green tea polyphenol epigallocatechin-3-gallate and cranberry proanthocyanidins act in synergy with cathelicidin (LL-37) to reduce the LPS-induced inflammatory response in a three-dimensional co-culture model of gingival epithelial cells and fibroblasts. Arch Oral Biol. 2015;60:845-53.

13. Cardoso CR, Garlet GP, Crippa GE, Rosa AL, Júnior WM, Rossi MA, et al. Evidence of the presence of T helper type 17 cells in chronic lesions of human periodontal disease. Oral Microbiol Immunol. 2009;24:1-6.

14. Hirota K, Yoshitomi H, Hashimoto M, Maeda S, Teradaira S, Sugimoto N, et al. Preferential recruitment of CCR6-expressing Th17 cells to inflamed joints via CCL20 in rheumatoid arthritis and its animal model. J Exp Med. 2007;204:2803-12.

15. Hosokawa Y, Nakanishi T, Yamaguchi D, Takahashi K, Yumoto H, Ozaki K, et al. Macrophage inflammatory protein 3alpha-CC chemokine receptor 6 interactions play an important role in CD4+ T-cell accumulation in periodontal diseased tissue. Clin Exp Immunol. 2002;128:548-54.

16. Nakata $H$, Tsubotani $Y$, Nii T, Hagi A, Inoue $Y$, Imamura T. Effects of olanexidine gluconate on preoperative skin preparation: an experimental study in cynomolgus monkeys. J Med Microbiol. 2017;66:678-85.

17. Hagi A, Iwata K, Nii T, Nakata H, Tsubotani $Y$, Inoue $Y$. Bactericidal effects and mechanism of action of olanexidine gluconate, a new antiseptic. Antimicrob Agents Chemother. 2015;59:4551-9.

18. Inoue $Y$, Hagi A, Nii T, Tsubotani Y, Nakata H, Iwata K. Novel antiseptic compound OPB-2045G shows potent bactericidal activity against methicillin-resistant Staphylococcus aureus and vancomycin-resistant Enterococcus both in vitro and in vivo: a pilot study in animals. J Med Microbiol. 2015;64:32-6.

19. Fujimoto R, Kamata N, Yokoyama K, Taki M, Tomonari M, Tsutsumi S, et al. Establishment of immortalized human oral keratinocytes by gene transfer of a telomerase component. J Jpn Oral Muco Membr. 2002;8:1-8.

20. Sugiyama A, Uehara A, Iki K, Matsushita K, Nakamura R, Ogawa T, et al. Activation of human gingival epithelial cells by cell-surface components of black-pigmented bacteria: augmentation of production of interleukin-8, granulocyte colony stimulating factor and granulocyte-macrophage colonystimulating factor and expression of intercellular adhesion molecule 1. J Med Microbiol. 2002;51:27-33.

21. Ohta K, Laborde NJ, Kajiya M, Shin J, Zhu T, Thondukolam AK, et al. Expression and possible immune-regulatory function of ghrelin in oral epithelium. J Dent Res. 2011;90:1286-92.

22. Stathopoulou PG, Benakanakere MR, Galicia JC, Kinane DF. Epithelial cell pro-inflammatory cytokine response differs across dental plaque bacterial species. J Clin Periodontol. 2010;37:24-9.

23. Jenkins S, Addy M, Wade W. The mechanism of action of chlorhexidine. A study of plaque growth on enamel inserts in vivo. J Clin Periodontol. 1988; 15:415-24.

24. Millhouse E, Jose A, Sherry L, Lappin DF, Patel N, Middleton AM, et al. Development of an in vitro periodontal biofilm model for assessing antimicrobial and host modulatory effects of bioactive molecules. BMC Oral Health. 2014;14:80

\section{Publisher's Note}

Springer Nature remains neutral with regard to jurisdictional claims in published maps and institutional affiliations.

Ready to submit your research? Choose BMC and benefit from:

- fast, convenient online submission

- thorough peer review by experienced researchers in your field

- rapid publication on acceptance

- support for research data, including large and complex data types

- gold Open Access which fosters wider collaboration and increased citations

- maximum visibility for your research: over $100 \mathrm{M}$ website views per year

At BMC, research is always in progress.

Learn more biomedcentral.com/submission 